REFORMA DO ENSINO JURIDICO.

\title{
Uma carta do prof. Braz de Sousa Arruda
}

"Meu caro amigo e distinto colega Prof. H.T."

Escrevo-lhe esta carta para lhe dar o meu ponto de vista sôbre a reforma do ensino jurídico.

Duas vêzes estudei o problema entre nós. A primeira foi em 1929, no trabalho publicado na Revista da Faculdade de Direito de São Paulo, volume 25.

Não havia então ainda a Universidade de São Paulo.

Pela segunda vez, no trabalho publicado na mesma Revista da Faculdade de Direito, volume XLI de 1946, em artigo sob título "A Faculdade de Direito, a Universidade e os problemas do ensino".

Vejamos agora os pontos capitais, segundo minha opinião, para uma reestruturação do nosso ensino jurídico.

Parece-me que não devemos deixar de levar em consideração a nossa experiência. Copiar sistemas estrangeiros sem maior cuidado é, segundo creio, perigoso. Ficarmos na mesma, inútil.

Devemos avançar cautelosamente, lembrando-nos sempre da lição de EisenmanN, no seu precioso trabalho "Les Sciences sociales dans l'enseignement supérieur du Droit" (Unesco), pág. 10.

Diz êle: “L'enseignement du droit a noué des lieux trop étroit avec les formes culturelles existantes, et il est trop bien enraciné dans les traditions, pour qu'il soit possible d'envisager des transformations radicales dans les pays ou cet enseignement existe depuis longtemps"

Vejamos como organizaria os cursos de bacharelado e de doutorado. 


\section{Bacharelado}

1.

1. Introdução à Ciência do Direito (aulas diarias).

2. Direito Público e Constitucional (Seminário de técnica Legislativa).

3. Direito Civil.

4. Economia Política.

5. Ciência das Finanças.

II.

1. Direito Civil.

2. Direito Penal.

3. Direito Constitucional Brasileiro (Seminário de Hermenêutica).

4. Direito Social.

5. Direito Judiciário (Teoria Geral).

III.

1. Direito Civil.

2. Direito Penal.

3. Direito Comercial.

4. Direito Judiciário Civil.

5. Direito Administrativo.

\section{IV.}

1. Direito Civil.

2. Direito Penitenciário.

3. Direito Comercial. 
4. Direito Judiciário Civil (Seminários de Deontologia e Psicologia Judiciária).

5. Direito Internacional Público.

V.

1. Direito Judiciário Penal.

2. Direito Internacional Privado.

3. Medicina Legal.

4. Prática do Processo (Seminários de Tática e Prática Judiciária).

5. Filosofia do Direito.

Cada uma das cadeiras do curso do Bacharelado deverá ter um Seminário, dirigido por tantos assistentes quantas forem as turmas de cinqüenta alunos. Os assistentes serão obrigados a dar, no mínimo, três Seminários diàriamente, sob orientação e responsabilidade do Professor Catedrático.

O curso do Bacharelado tem caráter eminentemente profissional.

Devemos esclarecer que o profissionalismo deve assentar em uma base eminentemente ciêntífica (Palacios - La Democratización de la enseñanza. José Lo Valvo - El problema universitário del profesionalismo y la investigación. Contra Cossio - El plan de estudos de Abogacia, que sustenta que a base do profissionalismo deve ser técnica e não científica.

Mudando sua orientação primitiva (La Reforma Universitária, p. 50 e 147).

A Iuta contra profissionalismo é a luta contra técnica.

O espírito está unido à obra artística, mas esta depende da técnica. 
A arte é uma técnica para produzir determinados estimulos estéticos (Barrenechea - Un idealismo estético. p. 175-176).

Técnica e espírito se entrelaçam. Isto é evidente quando se considere a profundidade do pensamento de Pascal e seu estilo admirável.

A técnica não é a máquina, é a tática da vida, como dizia Spengler (El hombre y la tecnica), existindo numerosas técnicas sem ferramentas, técnicas espirituais como o marxismo ou a técnica diplomática.

Queremos dar ao Bacharelado um caráter de formação profissional, sem prejudicar a formação cultural dos alunos.

A função principal do auxiliar do ensino é justamente trabalhar com os alunos no Seminário para que não tenha o ensino um caráter passivo, mas sim ativo.

Além disto, será necessário que se desenvolva o amor ao estudo e à pesquisa. Para isso é de grande conveniência orientar os alunos para a leitura na biblioteca, obrigando-os à leitura de certos livros fundamentais, como é usual na Grã-Bretanha, na Suécia, na Iugoslavia e na Faculdade de Direito da Universidade de Istambul na Turquia.

0 aproveitamento, eliminadas as provas parciais, será verificado por uma prova escrita, outra oral e pelos trabalhos práticos e de Seminários. Será um exame final único em que se levarão em consideração os trabalhos práticos, os estudos de Seminários e leitura na Biblioteca. Eor isso que pleiteio a criação de uma Biblioteca Circulante em todos Institutos de ensino.

Eliminados os exames parciais, teríamos aumentado o ano letivo podendo dedicar um mês a trabalhos exclusivamente práticos.

E' pouco mais ou menos o que faz na Escola de Prática Jurídica em Madrí.

O nosso ano letivo seria organizado assim: 
1. Inscrição ao Concurso de Habilitação $\quad \ldots \ldots . \quad \ldots \quad \ldots \quad 2$ a 15 de janeiro.

2. Concurso de Habilitação .... 1 a 28 de fevereiro.

3. Exame de $2 .^{a}$ época ...... $10^{a}$ quinzena de março.

4. Início dos cursos . . . . $10^{\circ}$ de março.

5. Períodos letivos ........ $10^{\circ}$ de março a 30 de junho.

$1 .^{\circ}$ de agôsto a 30 de setembro (aulas teóricas)

mês de outubro (trabalhos de seminário).

6. Férias escolares ..... . . mêses de julho e janeiro /fevereiro.

7. Exames .. . . . . . 2. ${ }^{\text {a }}$ quinzena de novembro: escritos; mês de dezembro: orais.

1 - Quanto às inscrições ao concurso de habilitação.

Atualmente são feitas de $\mathbf{2}$ a 20 de janeiro, sendo que as provas do concurso começam na $2 .^{a}$ quinzena de fevereiro.

Dever-se-ia reduzir o prazo de inscrições em 5 dias, o que possibilitaria que se iniciassem as provas em $1 .^{\circ}$ de fevereiro e não depois do dia 15.

Essa alteração faria com que fôsse possível começar o ano letivo rigorosamente em $10^{\circ}$ de março (aliás como a lei atual exige), e não em abril, como se tem feito, pelo menos na Faculdade.

Êsse mês ganho poderia ser dedicado aos trabalhos de seminário, que deveriam ser realizados no mês de outubro, após o encerramento dos trabalhos teóricos.

Quanto aos quinze dias, de junho, correspondentes ao período das provas escritas parciais, que serão abolidas, ganhos para a explanação de teoria, poderiam ser dados aos alunos na primeira quinzena de novembro para que 
pudessem preparar-se para os exames, que se iniciaríam em 16 de novembro.

Poder-se-ia mesmo estabelecer que os concursos para a cátedra e livre-docência fôssem sempre realizados nessa primeira quinzena de novembro, do que resultaria não serem as aulas suspensas para concurso.

\section{Seminários}

Durante o ano letivo seriam realizados pelo auxiliar de ensino, orientados pelo catedrático.

Entretanto no mês de outubro seria o catedrático que estaria à frente do seminário, não dispensada a cooperação do auxiliar de ensino.

O principal é o Professor orientar os alunos, ensiná-los a trabalhar e desenvolver o amor à leitura e a pesquisa.

Um plano de estudos nada significa por sí mesmo. O que é fundamental é o método. Não devemos transmitir mecânicamente um conjunto de conhecimentos já elaborados. Precisamos é de disciplina mental, desenvolvimento de aptidões, exercício da inteligência e da vontade, elevação da alma e aperfeiçoamento do coração, para que o aluno, por si mesmo, possa adquirir conhecimentos e opiniões próprias.

O plano de estudo é o coroamento, é um instrumento entregue ao corpo docente.

E' preciso democratizar o ensino, aperfeiçoar os métodos didáticos, e tornar o estudo atraente, moderno e arejado.

$O$ verdadeiro sistema consiste em ensinar ao estudante a trabalhar, criando hábitos de estudo e investigação.

Vê-se que sou favorável aos estudos do Seminário e à pesquisa.

Acho porém indispensável as preleções do Catedrático. $O$ ensino por meio de preleções tem sido atacado injustamente. Reputo-o indispensável. Há uma página admirável que torna claro o meu pensamento. Vou reproduzi-la: 
"Quelque importante que soit l'étude personnelle, l'enseignement oral du professeur, dans tous les ordres de science, a toujours été regardé à bon droit comme le meilleur moyen d'apprendre. “Je m'étonne, disait Maldonat aux étudiants de Paris, qu'il y ait (des élèves) qui, animés d'un ardent désir de pénétrer dans cette science, dêdaignet de fréquenter les leçons de maîtres habiles qu'ils pourraient entendre, et se jettent avidement, tantôt sur un livre, tantôt sur un autre (libros lectitando et, ut apertius dicam, errando) Cependant. il vaudrait mieux renoncer à tous les autres (moyens d'apprendre qu'à l'assistance aux classes), car les longues explications, les développements du maître, les inflexions de sa voix, son regard, son geste, son action, mettent pour ainsi dire sous les yeux les choses plus difficiles et les plus obscures, ce que les livres ne sauraient faire. Le maître et les livres se servent souvent des mêmes termes pour dire les mêmes choses, mais, sortis de la bouche du maître, qui y joint l'expression de ses convictions, ils nous frappent davantage et se gravent plus profondément dans l'esprit. Dans tout le cours des études, il n'y a pas de temps mieux employé et moins pénible que celui qu'on passe aux leçons du maître. Rien ne se retient et ne se sait mieux que ce qu'on apprend de leurs bouches". De ratione studendi theologiae, ad auditores Parisinos, p. 27. Essa passagem foi traduzida pelo P. Prat, Maldonat et l'Université de Paris au XVI-e siècle, p. 274-275.

Vejamos agora o curso de

\section{Especialização e Doutorado}

Secção de Direito Público.

I.

1. Direito Constitucional Comparado

2. Direito Internacional aprofundado

3. Teoria Geral do Estado. 
II.

1. Política Mundial.

2. Organização e Instituições Internacionais.

3. Técnica Legislativa.

Secção de Direito Privado.

I.

1 Direito Romano.

2. Direito Civil Comparado.

3. Direito Comercial Comparado.

II.

1. Direito Internacional Privado.

2. História do Direito Nacional.

3. Problemas Jurídicos Contemporâneos.

Secção de Ciências Penais.

I.

1. História do Direito Penal.

2. Criminologia.

3. Direito Penitenciário.

II.

1. Direito Penal aprofundado.

2. Direito Penal comparado.

3. Direito Penal Internacional. 
Secção de Cultura Judicịal.

I.

1. Deontologia Forense.

2. Psicologia Judiciária.

3. Filosofia Judicial.

II.

1. Tática e Prática Judiciária.

2. História do Direito Nacional.

3. Problemas Jurídicos contemporâneos.

A Cadeira de Filosofia do Direito é comum às quatro secções do Curso de Doutorado.

Evidentemente em cada cadeira do Doutorado haverá, como no Bacharelado, um seminário especializado.

Para mim, terminado o segundo ano do Curso Jurídico, os alunos do Bacharelado poderão se inscrever em uma das secções de alta cultura do Curso de Especialização e obter um certificado de aproveitamento. E uma maneira interessante de se dar flexibilidade, ao curriculo. Há um diploma único e certificados de aproveitamento e especialização em uma das secções do Curso de Especialização e Doutorado. É uma preparação também para a defesa de teses, o que possibilita o título de Doutor em Ciências Jurídicas e Sociais.

Um longo e saudoso abraço do seu de todo coraçã.o.

Braz de Sousa Arruda. 